\title{
Determining Factors in the Perception of Cyberbullying in Victimized Adolescents: Psych educational Implications
}

\author{
Inmaculada Fernández-Antelo ${ }^{1}$, Isabel Cuadrado-Gordillo ${ }^{2}$,Guadalupe Martín-Mora \\ Parra $^{3}$ \\ ${ }^{1}$ Department of Psychology. University of Extremadura, Badajoz, Spain
}

\begin{abstract}
.
The knowledge of the perceptual structure that victims have of the cyberbullying phenomenon favors the adjustment of prevention and intervention programs. However, there are few studies that try to find out what are the factors that influence the construction of a certain perceptual structure on cyberbullying, let alone those that focus on a population such as victimized adolescents. This paper aims to know the perceptual structure that victimized adolescents have about cyberbullying, as well as the factors that determine the construction or modification of this structure. The sample consisted of 2148 adolescents ( $49.1 \%$ girls) of ages from 12 to $16(\mathrm{M}=13.9 ; \mathrm{SD}=1.2)$. The results have shown that in the victims' perceptual structure the key factor is the intention to harm, closely linked to the asymmetry of power and publicity. Anonymity, revenge and repetition are also present in this structure, although its relationship with cyberbullying is indirect. Likewise, the results indicate that victimization experiences, as well as the intensity of the aggressions suffered, play a mediating role in the formation and modification of this perceptual structure. These results allow defining risk factors that would promote the durability of the victim's role and the conversion of victims into poly-victims. Knowledge of this perceptual structure provides key elements for the design of psychoeducational prevention and intervention programs in cyberbullying.
\end{abstract}

Keywords: digital violence; intentionality; prevention; risk factors; secondary education

\section{Introduction}

After its emergence, the use and popularity of the Internet has extended to the point that it is difficult to conceive life without this virtual network. One of the main achievements that the Internet has brought is the creation of a space which, although not physical, is very real: cyberspace. Cyberspace surpasses physical and social limits, and blurs the norms defining when and how to interact. This virtual space has also created numerous cyberscenarios that have become the bases for the virtual relationships that have arisen in diverse and numerous social networks. Social networks and instant messaging applications allow users to interact socially either person-to-person or within groups. This is the case of the social networks that 


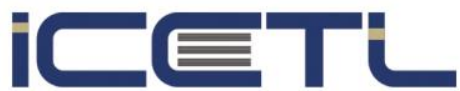

21-23 FEBRUARY, 2020

\section{$3^{\text {rd }}$ International Conference on Research in EDUCATION, TEACHING and LEARNING}

ROME, ITALY

are most popular among teenagers and young adults: Facebook, Instagram, Twitter, and WhatsApp (Spies \& Margolin, 2014).

Access to these tools from an early age is also exposing children and teenagers to dangerous situation, not only in physical contexts, but also in virtual ones, and which they often know little or nothing about. Inability to control the use children and teenagers make of the Internet and the lack of supervision by caregivers and parents are directly related to a series of negative consequences that have a direct influence on the daily lives of these young people (Spada, 2014).

\subsection{Cyberbullying: a construct in continuous definition}

The aggressions that occur in cyber scenarios have generally been grouped under the term cyberbullying, an emergent concept that researchers are still debating (Pieschl et al., 2013).

Some authors consider the conceptualization of cyberbullying about the existence of certain characteristics or criteria that enable one to differentiate between cyberbullying and other acts of aggression carried out through technological and cyber means. One of these criteria is related to the aggressor's intent to hurt - to inflict pain, fear, or harm on the victim. In the cyber context, the detection and application of this criterion involves certain difficulties related to the lack of face-to-face communication, the ignorance in many cases of the identity of the aggressor, or the aggressor's ignorance of the consequences that their actions have for others (Naruskov et al., 2012). On the other hand, Shariff (2015) states that cyberbullying can also be unintentional for digital natives, or children growing up immersed in digital media, because often fail to appreciate the difference between jokes and intentional harm.

Another criterion identifying cyberbullying is the repetition of the aggression. In the case of cyberbullying, repetition does not necessarily imply a succession of violent acts from the same attacker. Slonje et al. (2013) believe that the victim can experience a single aggression on numerous occasions due to the permanent and public nature of virtual communication. Even though private and compromising material owned by the victim may be sent only once, it may be seen and then broadcast by several people, causing the victim more pain, and lasting a longer time (Dooley et al., 2009). Moreover, Langos and McomL (2012) relates repetition to intent in cases of direct cyberbullying, understanding that when abuse occurs again and again it is clearly shown not to be an isolated or inadvertent act, but an intentional one.

A third criterion attributed to the definition of cyberbullying is the existence of an imbalance of power between the aggressor and victim. According to Grigg (2010), in the cyber context the imbalance is materialized in situations where the victim cannot easily defend themselves. This asymmetry of power between the aggressor and victim does not refer to the physical, emotional, or psychological superiority of the aggressor, but to an asymmetry in the ICT domain (Slonje et al., 2013). Knowledge of and competence in using ICT tools provides access to the victims' hitherto private virtual spaces, so as to disseminate the information or materials stored there, steal their identity, create obstacles against identifying the aggressor, etc. (Casas et al., 2013). Grigg (2010) also alludes to a social imbalance caused by the difference in status in favour of the aggressor, which is augmented by the support of the group 


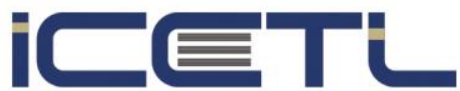

21-23 FEBRUARY, 2020

\section{$3^{\text {rd }}$ International Conference on Research in EDUCATION, TEACHING and LEARNING}

ROME, ITALY

or social network in which the aggressor may be very popular. Other authors interpret the imbalance of power in a symbiotic relationship with other criteria, such as the intent to hurt (Nocentini et al., 2010) or the anonymous or public nature of the aggressor (Dooley et al., 2009; Slonje \& Smith, 2008).

A fourth criterion which would facilitate the differentiation between a cyber-aggression and an episode of cyberbullying is the anonymity which protects the aggressor. The possibilities of concealment offered by technological and cyber media without the need for any very advanced technical knowledge can significantly influence the way people resolve their conflicts. Specifically, Kowalski et al. (2012) argue that anonymity may encourage some people to act in a way that they would never do in real life. The difficulties to be identified may help to disinhibit to cyberbullies, making it easier to say, write o send things they normally would not in physical contexts. Nevertheless, while anonymity is considered a specific criterion of cyberbullying, there are studies that show that most of the victims recognize their cyber aggressors and identify them as peers belonging to their school or to their closest social environment (e.g., Mishna et al. 2010; Slonje et al., 2013).

The final defining criterion of cyberbullying corresponds to the open and uncontrolled dissemination of the aggressive behaviour, i.e., advertising it. Despite this being one of the most widely occurring criteria in acts of cyberbullying (Patchin \& Hinduja, 2010), some researchers caution that it should not be considered an essential characteristic defining and delimiting an act of cyberbullying, although they do recognize its relevance in reflecting the seriousness of the aggression (Nocentini et al., 2010).

\subsection{What do teenagers understand by cyberbullying?}

Previous studies have addressed the establishment of first- and second-order criteria by analyzing whether the combination and interaction of some of them could be key indicators to differentiate cyberbullying from cyber aggression. Thus, Bass et al. (2013) focus on the intent and repetition criteria, analyzing their use by 287 children aged 11-12. Their results show that the perception of these criteria in the cyber context is ambiguous and arbitrary, and it is therefore impossible to determine whether the relationship between the two is the criterion most often used to define cyberbullying. Nevertheless, Menesini et al. (2012) find that European adolescents tend to relate the repetition and the intent criteria in the sense that if a behavior is repeated then it cannot be classified as unintentional.

The greater relevance of certain criteria over others is also studied by Nocentini et al. (2010) with samples from different European countries. Their results show that there are two criteria that adolescents attach particular importance to in differentiating a cyber-aggression from an episode of cyberbullying: intent and imbalance. Dredge et al. (2014), however, find that there are very few young Australians who take the intent to hurt and imbalance of power as essential components in the definition of cyberbullying. Instead they emphasize the importance of other possible components such as the impact that the aggression has on the victim. Nocentini et al. (2010) and Menesini et al. (2012) indicate that, although adolescents consider anonymity in determining the impact that a cyber-aggression has on the victim, they do not see it as a defining characteristic of cyberbullying. These authors also suggest that adolescents do not consider the 'advertising' of the abuse to be a criterion classifying a 


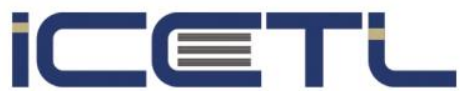

21-23 FEBRUARY, 2020

\section{$3^{\text {rd }}$ International Conference on Research in EDUCATION, TEACHING and LEARNING}

ROME, ITALY

cyberaggression as cyberbullying. Sticca and Perren (2013), however, indicate that Swiss adolescents attach particular importance to the public dimension of cyber aggressions, and consider it to be a defining characteristic of cyberbullying that determines the severity of the harm caused.

In the same line as the above studies, Naruskov et al. (2012) analyse the perceptions that 20 Estonian secondary education pupils aged 9-15 have about cyberbullying. They also investigate the application of defining criteria to the different forms in which this phenomenon is manifested. Their results show that adolescents consider five criteria to define cyberbullying: intent to hurt, imbalance of power, repeated aggressive behaviour, anonymity, and advertising. These authors warn, however, that adolescents do not simultaneously apply these criteria to the variations of cyberbullying that researchers have defined. Only visual abuse (characterized mostly by the dissemination of photos and videoclips) and impersonation are, in the opinion of the pupils, what best represent the construct of cyberbullying, as against exclusion and written or spoken aggression.

Although previous research studies have addressed the perceptions adolescents have about cyberbullying, their results are disperse in the aspects dealt with, and difficult to compare due in part to the lack of coincidence in the data acquisition instruments used and the small size of some of the samples. Moreover, the contributions of previous studies on this topic have focused primarily on the perception of cyberbullying construct without considering the interpretation that adolescents make of the different modes in which this phenomenon can manifest. The approach to the perceptions that adolescents have of this phenomenon requires knowledge of both the factors or criteria that shape their definitions of this concept and of what they think are the possible behaviours in which cyberbullying may be manifest. For adolescents, the definition of this construct may be complex. However, the detailed description of its application was expected to be simpler for them, and would thus facilitate our acquisition of a more global and comprehensive vision of the bases of their perceptions of cyberbullying. This study allows to determine the criteria that victim adolescents use to differentiate a cyberaggression from a cyberbullying episode, and to identify what types of cyber abuse they consider to be cyberbullying. The objectives pursued in this study were: (a) to determine the perceptions victims have about cyberbullying and cyber abuse; and (b) to analyse the influence of experiences of cybervictimization on the perception of cyberbullying and its various forms.

\section{Method}

\subsection{Participants}

The sample consisted of 2148 adolescents $(50.9 \%$ boys and $49.1 \%$ girls; $\mathrm{SD}=.5)$ of ages from 12 to $16(\mathrm{M}=13.9 ; \mathrm{SD}=1.2)$. To select the participants, we applied a stratified multistage, approximately proportional, sampling procedure with conglomerates and random selection of groups in public secondary schools in which Compulsory Secondary Education (ESO) is taught. The strata considered were the provinces and geographical areas of Extremadura (Spain), selecting towns in the north, south, east, and west of the region, and taking their different socio-cultural contexts into account. The conglomerates used were the secondary 


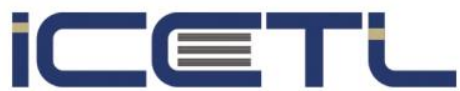

21-23 FEBRUARY, 2020

\section{$3^{\text {rd }}$ International Conference on Research in EDUCATION, TEACHING and LEARNING}

ROME, ITALY

schools. In each school, one of the four courses making up the ESO (1st year, ages 12-13; 2 nd year, age 14; 3rd year, age 15; and 4th year, age 16) was selected at random.

\subsection{Instrument}

The instrument used for the collection of data was a questionnaire of 28 questions grouped into nine blocks. The first block consists of three questions that allow one to identify whether the adolescents consider themselves to be aggressors, victims, or witnesses of cyberbullying. From this identification, we can analyse how they behave in the rest of the questionnaire, i.e., what perception they have of the phenomenon of cyberbullying. These first three questions also provide insight into how often during the last three months they had committed, been victims of, or observed cyberbullying episodes. The scale used comprised four values: 'never', 'once or twice, 'once a week', and 'several times a week'. This scale has been used in many studies analysing the prevalence of cyberbullying (e.g., Del Rey et al., 2015; Huang \& Chou, 2013). A respondent is considered to have played the role of aggressor, victim, or witness when they say they have been involved at least 1 or 2 times in some of the behaviours they are presented with. The item used to identify the victims is the following, for which they have to indicate indicate how often during the past three months they had suffered any of the following behaviours: "(1) I have been insulted through the mobile phone or Internet; (2) I have been threatened or blackmailed through the mobile phone or Internet; (3) lies and false rumours have been spread about me through the mobile phone or Internet; (4) I have been removed from contact lists on social networks, group chats, or emails so as to exclude me; (5) I have had someone pretend to be me, and my email, private chat rooms, or social network profile have been accessed without my permission; (6) they have sent by mobile phone or Internet incriminating photos or videos, which are denigrating or demeaning to me; (7) they have recorded fights in which I participated and spread them through mobile phones, social networks, or other cyber means; (8) they have sent sexual or erotic type of content in which I took part." The items used to identify witnesses and aggressors are similar. For example, instead of asking them to indicate whether they felt threatened, we asked if they have threatened another student (in the case of the aggressors) or have seen another student threatened (for the witnesses).

A reliability analysis of the instrument showed satisfactory internal consistency of the blocks of items aimed at identifying the victims (Cronbach's alpha: $\alpha=.84$ ).

The questionnaire's 25 remaining questions aimed at determining the perception of cyberbullying and the modalities in which it manifests itself. The 25 questions are grouped into 8 thematic blocks corresponding to the different modes in which this phenomenon manifests itself in accordance with the "type of behaviour" criterion: insults (including homophobia), threats (including blackmail), spreading false rumours, exclusion (from contact lists, social networking, etc.), identity theft, sexting, posting denigrating images or videos, and recording and disseminating physical aggressions (Huang \& Chou, 2010; Kowalski et al., 2012). Each but one of these blocks comprises 3 questions. The exception is the "insults" mode for which there are 4 questions to try to cover the great variety of types of insults that were encountered. With these questions, we can determine the perception adolescents have of behaviours regarded as manifestations of cyberbullying, and the criteria they use to define 


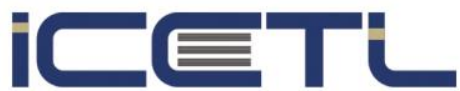

21-23 FEBRUARY, 2020

\section{$3^{\text {rd }}$ International Conference on Research in EDUCATION, TEACHING and LEARNING}

ROME, ITALY

those behaviours. The scale comprises 5 values to indicate the degree of agreement with each of the items presented (strongly agree, agree, neither agree nor disagree, somewhat disagree, and disagree). Multi-item measurements help to minimize the perceptual bias of the respondent (Selkie et al., 2015). A reliability analysis showed satisfactory internal consistency in the block of items designed to access the perceptions of cyberbullying (Cronbach's $\alpha=.79$ ). We also calculated the degree of internal consistency for each of these 8 thematic blocks. The following are the results: insults $(\alpha=.82)$, threats $(\alpha=.71)$, spreading false rumours $(\alpha=.76)$, exclusion $(\alpha=.78)$, identity theft $(\alpha=.85)$, sexting $(\alpha=.79)$, posting denigrating images or videos $(\alpha=.77)$, and recording and disseminating physical aggressions $(\alpha=.82)$.

\subsection{Procedure}

With this being a study involving minors, it was necessary to have the parents' consent, and the approval of the Regional Administration's education inspectors and of the different schools' management teams. To obtain the parents' consent, they were sent a letter describing the nature of the study, the use that would be made of the data, and the commitment to confidentiality and anonymity. This letter was accompanied by a form for the parents to forward to the school if they did not want their children to participate in the study.

The education inspectors and management teams were sent a report in which the objectives of the research, the procedures, and the guarantee of anonymity of the participants were detailed. This was thus in full compliance with the ethical standards governing secondary schools.

The data acquisition procedure followed once the parents and school authorities had been informed consisted in the researchers going to each of the selected schools in turn, where they distributed the questionnaires in each of the classes, and remained in those classrooms until all of the participants who had voluntarily wanted to take part had handed them back filled in.

\subsection{Data analysis}

From the data collected with the questionnaire, it was to identify the adolescents who define themselves as victim, and performed a exploratory factor analysis to determine whether their definitions of cyberbullying varied according to their role in the different cyberbullying situations they themselves experience.

\section{Results}

A total of 328 adolescents declared themselves to be victims of cyberbullying (131 boys and 197 girls). With respect to the variable corresponding to the type of aggressive behaviour, the descriptive results show that cybervictims are subject to more than one form of cyberbullying (Table 1). 


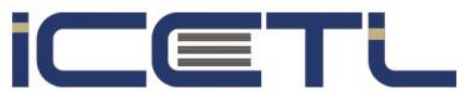

21-23 FEBRUARY, 2020 $3^{\text {rd }}$ International Conference on Research in EDUCATION, TEACHING and LEARNING

Table 1: Distribution of cybervictims in the different modes of cyberbullying

\begin{tabular}{|l|c|}
\hline & Cybervictims \\
\hline Threats & 141 \\
\hline Spreading false rumours & 198 \\
\hline Insults & 136 \\
\hline Exclusion & 93 \\
\hline Impersonation & 87 \\
\hline Sexting & 49 \\
\hline Physical attacks & 58 \\
\hline Videoclip & 167 \\
\hline
\end{tabular}

The resulting KMO index of .85 and a significance level in the Bartlett sphericity test of .001 , provided the sufficient guarantee of reliability of the results. The principal component analysis showed that, although in principle up to 7 factors were detected as present in the concept adolescents have of cyberbullying, only 4 explain the variability of the responses and provide a closer approximation to the general perception that more than $88 \%$ of the participants has (Table 2).

Factor 1. Intent to hurt. This factor includes those responses in which the victims consider the intent of causing a social or psychological injury to others to be a necessary condition to classify a cyberaggression as cyberbullying. This factor accounts for $43.77 \%$ of the variance (Table 2), has an internal reliability of $\alpha=.83$, and a mean factor loading of .57 .

Factor 2. Advertising. This factor includes the situations in which adolescents indicate that there has to be dissemination of the cyberaggression, through either the Internet or cellular telephony, as a necessary condition for it to be classified as cyberbullying. This factor accounts for $23.17 \%$ of the variance (Table 2), has a moderate internal reliability $(\alpha=.69)$, and a mean factor loading of .55 .

Factor 3. Imbalance of power. This factor includes behaviour that the pupils classify as cyberbullying and in which they perceive the existence of an asymmetry between the aggressor and victim, not just social or psychological, but also regarding the mastery of technological media. This factor accounts for $13.78 \%$ of the variance (Table 2), has high internal reliability $(\alpha=.77)$, and a mean factor loading of .53 .

Factor 4. Form of social relationship. This factor includes the cyberbullying situations that adolescents interpret as a form of fun and relationship among peers. This factor accounts for $10.01 \%$ of the variance (Table 2$)$, has a moderate internal reliability $(\alpha=.78)$, and a mean factor loading of .50 . 


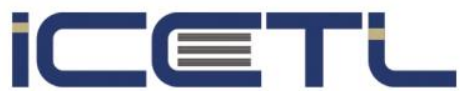

21-23 FEBRUARY, 2020

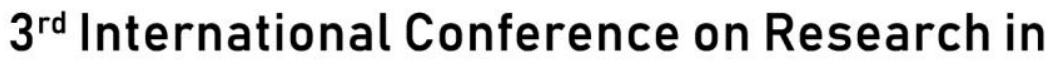
EDUCATION, TEACHING and LEARNING

ROME, ITALY

Table 2: Total variance explained by the componets

\begin{tabular}{|l|c|c|c|c|c|c|}
\hline & \multicolumn{3}{|c|}{ Initial eigenvalues } & \multicolumn{3}{c|}{ Extraction sums of squeared loadings } \\
\hline Component & Total & \% variance & Cumulative \% & Total & \% variance & Cumulative \% \\
\hline 1 & 5.81 & 43.77 & 43.77 & 5.81 & 43.77 & 43.77 \\
\hline 2 & 3.16 & 23.17 & 66.94 & 3.16 & 23.17 & 66.94 \\
\hline 3 & 1.98 & 13.78 & 80.72 & 1.98 & 13.78 & 80.72 \\
\hline 4 & 1.43 & 10.01 & 90.73 & 1.43 & 10.01 & 90.73 \\
\hline 5 & 0.68 & 5.39 & 96.12 & & & \\
\hline 6 & 0.42 & 2.82 & 98.94 & & & \\
\hline 7 & 0.17 & 1.06 & 100 & & & \\
\hline
\end{tabular}

Extraction method: Principal component analysis

The factor extraction indicates that there are three key criteria that the victims use to define cyberbullying: 'intent to hurt', 'advertising', and 'imbalance of power'. Nevertheless, they only attribute all three criteria simultaneously to impersonation (Table 3).

Table 3: Total variance explained by the four principal components: cybervictims

\begin{tabular}{|l|c|c|c|c|}
\hline & \multicolumn{4}{|c|}{ Components } \\
\hline & $\mathbf{1}$ & $\mathbf{2}$ & $\mathbf{3}$ & $\mathbf{4}$ \\
\hline Definition of cyberbullying & .742 & .541 & .529 & \\
\hline Threats & .529 & .487 & & \\
\hline Spreading false rumours & .453 & & & .348 \\
\hline Insults & & & & .364 \\
\hline Exclusion & .587 & .391 & & \\
\hline Impersonation & .615 & & .322 & \\
\hline Sexting & .628 & & .327 & \\
\hline Physical attacks & .503 & .569 & & \\
\hline Videoclip & .416 & .488 & & .501 \\
\hline
\end{tabular}

Extraction method: Principal component analysis

Rotation method: Varimax. The rotation converged in 8 iterations

The results for the intentionality factor show that victims perceive all the forms of cyber abuse considered in the present study except insults to be committed with the objective of causing harm to peers. The results also show that adolescents establish a link between the intent and advertising criteria to define threats and harassment as cyberbullying. But in neither of these modes of abuse is imbalance a relevant criterion. Abuse associated with spreading rumours and insults is perceived simply as behaviour that facilitates interaction and communication among peers. The content of the messages, as well as the consequences that they may have for others, are relativized and justified as part of adolescents' social dynamics, and seen as not necessarily going to harm others. Exclusion is interpreted as behaviour aimed at inflicting harm on the victims when they feel rejected from the groups that they were members of. The intent criterion is also present in the perception adolescents have of recording and disseminating acts of physical aggression. 


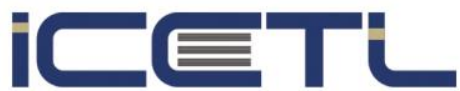

21-23 FEBRUARY, 2020

\section{$3^{\text {rd }}$ International Conference on Research in EDUCATION, TEACHING and LEARNING}

ROME, ITALY

\section{Discussion}

This study has shown that, of the 5 criteria considered to be identifiers of cyberbullying, Spanish adolescents have recourse to just three: intent to hurt, imbalance of power, and advertising. The lack of references to repeated aggressive behaviour may be motivated, as noted by Nocentini et al. (2010), by the relationship between this criterion and advertising. Adolescents today understand that, even though the actual act of cyberaggression may occur only once, its rapid and uncontrolled spread via the Internet or mobile telephony means that the hurt is repeated.

Neither do Spanish adolescents believe that anonymity should be considered a determining factor differentiating a cyberaggression from an episode of cyberbullying. In line with these results, Dredge et al. (2014) argue that adolescents relativize this criterion because many of them know, or have reasonable suspicions about, the identity of the aggressors. In most cases they are acquaintances who belong to the close environment of the victim. The high degree of continuity between off-line and on-line contexts in which adolescents interact fosters the transfer to cyberspace of interpersonal relationships that started in physical environments (Subrahmanyam et al., 2006). In this sense, cyberbullying episodes are a continuation of aggression experienced in the school context. The creation of peer support groups can promote the learning of how to resolve interpersonal conflicts, and the development of a capacity for empathy. The establishment and consolidation of a safety net in the form of presential adolescent support groups in classroom contexts, so important at this stage of a person's development, can foster the acquisition of prosocial attitudes and behaviours, and reduce instances of cyberbullying as well as encourage the reporting of such instances.

Regarding the intent criterion, the adolescents have no doubts about including it as a defining criterion of cyberbullying. Its high factor loading relative to those of the other factors shows that the adolescents consider it to be a key identifier of cyberbullying, as indeed has been noted in other studies (Bass et al., 2013). Nevertheless, there are still many unanswered questions concerning this criterion. One, for instance, is whether intent has to be detected in the aggressor or if it is sufficient that the victim perceives the abuse as directed at causing them deliberate harm. In a cyber context, in which the aggressor's identity can be hidden, it is difficult to be sure that there is intent in the aggressive behaviour. Thus, Dredge et al. (2014) suggest that the perception of intent may need to be replaced by the real impact that the aggression causes the victim. Other researchers argue that the understanding and relevance of the intent to harm as a determining factor of cyberbullying can not be understood without relating this criterion with that of the imbalance of power (Nocentini et al., 2010).

For the victims, with intentionality being the primary factor, followed by advertising, while the imbalance of power is relegated to a background role. Knowing the identity of the aggressor and the consequences that their actions have for the victim appears to play a major part in understanding these results. Menesini et al. (2012) understand the imbalance of power not only as reflecting an asymmetry of status, but also as a dynamic of micro-processes of action and reaction. Thus, if the aggressor knows the consequences that their abusive actions have for the victim then this reinforces their perception of power. The decline in the score 


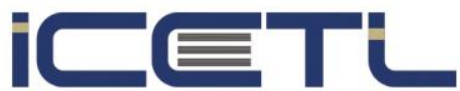

21-23 FEBRUARY, 2020

\section{$3^{\text {rd }}$ International Conference on Research in EDUCATION, TEACHING and LEARNING}

ROME, ITALY

assigned to intent can be explained by the normalization that these adolescents make of their abusive behaviour as prosocial patterns of interaction with their peers (Cuadrado, 2012).

Slonje et al. (2013) note the influence that knowledge of the aggressor's identity may have on the victim's perception of imbalance of power. If the identity is unknown then feelings of greater helplessness, frustration, and distrust undermine their possibilities of defence, putting them at a lower power status than their aggressor. Conversely, if they know or suspect who is behind the abuse then they can take some action to stop the aggression or mitigate its effects. A result is a reduction of the power asymmetry with the aggressor, since the victim has a perception of greater control (Sticca \& Perren, 2013).

In this scenario, there appears another factor which we have termed 'forms of social relationship' showing that, for these adolescents, verbal (insults and spreading false rumours) and visual (publication of videoclips) aggressions, far from being interpreted as forms of cyberbullying, are considered to be mechanisms that foster and facilitate their communication and interaction. In this sense too, Straude-Müller et al. (2012) note that cyber verbal abuse is not only less serious but also sometimes goes unnoticed by adolescents since they have internalized and normalized these offensive behaviours as seemingly innocuous patterns of social relationship.

Apart from its contribution to understanding the various perceptions of cyberbullying, the present study has provided a certain access to the interpretation that adolescents make of the different modes in which this phenomenon occurs. In particular, the results show that, taking as referent the definition that the adolescents attribute to this construct, they only recognize impersonation or identity theft as being cyberbullying. For none of the other modes do they transfer simultaneously the three criteria of intent, imbalance, and advertising which, in their opinion, must concur for an act of cyberaggression to be classified as cyberbullying.

\section{Conclusion}

Despite the proliferation of research on cyberbullying in the last decades, important questions remain about the conceptual definition of this phenomenon. The present results are consistent with the suggestions made by Slonje et al. (2013) about the need to consider in greater depth the delimitation of the criteria that define this construct. If researchers are finding it hard to reach an consensus definition of cyberbullying, it is even harder for the adolescents themselves. This is a population for whom the patterns of communication and interaction among peers differ from those of preceding generations. For them, ICTs form the essence of the instruments they use for connection and relationships with not only their closest sociocultural environment but also another virtually constructed environment to which they increasingly attach ever greater importance.

The study of the dimensions and characteristics specific to cyberbullying allows one to redefine this construct so as to design tighter and more effective prevention and intervention programs. The numerous controversies and contradictions that still exist about the boundary defining this phenomenon show the need to undertake further research focused on the perception that parents, educators, and adolescents have of cyberbullying. If the perception of those involved in this type of cyberaggression is very different from how researchers 


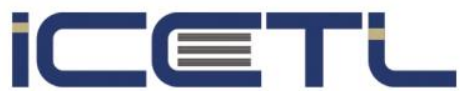

21-23 FEBRUARY, 2020

\section{$3^{\text {rd }}$ International Conference on Research in EDUCATION, TEACHING and LEARNING}

ROME, ITALY

conceptualize it, this will not only mean that we are faced with the description of quite different realities, but also that the effectiveness of prevention and intervention programs will be undermined.

\section{Acknowledgment}

This paper is an output of the research project IB16011 financed by the Government of Extremadura and funds Feder.

\section{References}

[1] Spies Shapiro, L. A. and Margolin, G. (2014). Growing up Wired: Social Networking Sites and Adolescent Psychosocial Development, Clinical Child and Family Psychology Review, vol. 17, pp. 1-18.

[2] Spada, M. M. (2014). An overview of problematic Internet use. Addictive Behavior, vol. 39(1), pp. 3-6.

[3] Pieschl, S., Porsch, T., Kahl, T. and Klockenbusch, R. (2013). Relevant dimensions of cyberbullying - Results from two experimental studies, Journal of Applied Developmental Psychology, vol. 34(5), pp. 241-252.

[4] Naruskov, K., Luik, O., Nocentini, A. and Menesini, E. (2012). Estonian students' perception and definition of cyberbullying, Trames, vol. 16(66/61), pp. 323-343.

[5] Shariff, S. (2015). Sexting and cyberbullying. Defining the line for digitally empowered kids. New York: Cambridge University Press.

[6] Slonje, R., Smith, P. K and Frisén, A. (2013). The nature of cyberbullying, and strategies for prevention, Computers in Human Behavior, vol. 29, pp. 26-32.

[7] Dooley, J., Pyzalski, J. and Cross, D. (2009). Cyberbullying Versus Face-to-Face Bullying. A Theoretical and Conceptual Review, Zeitschrift für Psychologie/Journal of Psychology, vol. 217, pp. 182-188.

[8] Langos, C. and McomL, L. G. (2012). Cyberbullying: The change to define, Cyberpsychology, Behavior, and Social Networking, vol. 15(6), pp. 285-289.

[9] Grigg, D. W. (2010). Cyber-aggression: definition and concept of cyberbullying, Australian Journal of Guidance and Couselling, vol 20(2), pp. 143-156.

[10] Casas, J.A., Del Rey, R. and Ortega, R. (2013). Bullying and cyberbullying: Convergent and divergent predictor, Computers in Human Behavior, vol. 29(3), pp. 580-587.

[11] Nocentini, A., Calmaestra, J., Schultze-Krumbholz, A., Scheithauer, H., Ortega, R. and Menesini, E. (2010). Cyberbullying: labels, behaviours and definition in three European countries, Australian Journal of Guidance Counseling, vol. 20, pp. 129-142.

[12] Kowalski, R. M., Limber, S. E. and Agatston, P. W. (2012). Cyberbullying: Bullying in the digital age, 2nd ed. Malden, MA: Wiley-Blackwell. 


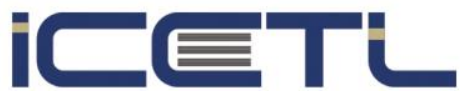

21-23 FEBRUARY, 2020

\section{$3^{\text {rd }}$ International Conference on Research in EDUCATION, TEACHING and LEARNING}

ROME, ITALY

[13] Patchin, J. W. and Hinduja, S. (2010). Changes in adolescent online social networking behaviors from 2006 to 2009, Computers and Human Behavior, vol. 26, pp. 1818-1821.

[14] Mishna, F., Saini, M., \& Solomon, S. (2009). Ongoing and online: Children and youth's perceptions of cyber bullying, Children and Youth Services Review, vol. 31(12), pp. 1222-1228.

[15] Dredge, R., Gleeson, J. and de la Piedad, X. (2014). Cyberbullying in social networking sites: An adolescent victim's perspective, Computer in Human Behavior, vol. 36, pp. 13-20.

[16] Bass, N., de Jong, M. D. and Drossaert, C. H. (2013). Children's perspectives on cyberbullying: insights based on participatory research, Cyberpsychology, Behavior, and Social Networking, vol. 16(4), pp. 248-253.

[17] Menesini, E., Nocentini, A., Palladino, B. E., Frisén, A., Berne, S., Ortega-Ruiz, R., et al. (2012). Cyberbullying definition among adolescents: A comparison across six European countries, Cyberpsychology, Behavior and Social Networking, vol. 15(9), pp. 455-463.

[18] Sticca, F. and Perren, S. (2013). Is cyberbullying worse than traditional bullying? Examining the differential roles of medium, publicity, and anonymity for the perceived severity of bullying, Journal of Youth and Adolescence, vol. 42(5), pp. 739-750.

[19] Vandebosch, H. and Van Cleemput, K. (2008). Defining cyberbullying: A qualitative research into the perceptions of youngsters, Cyberpsychology \& Behavior, vol. 11, pp. 499-503.

[20] Del Rey, R., Casas, J.A., Ortega-Ruiz, R., Schultze-Krumbholz, A., Scheithaver, H., Smith, P., Thompson,F., Barkoukis, V., Tsorbatzoudis, A., Brighi, A., Guarini, A., Pyzalski, J. and Plichta, P. (2015). Structural validation and cross-cultural robustness of the European Cyberbullying Intervention Project Questionnaire, Computers in Human Behavior, vol. 50, pp. 141-147.

[21] Huang, Y. and Chou, C. (2010). An analysis of multiple factors of cyberbullying among junior high school students in Taiwan, Computers in Human Behavior, vol. 26, pp. 1581-1590.

[22] Selkie, E., Fales, J.L. and Moreno, M.A. (2015). Cyberbullying prevalence among US middle and high school-aged adolescents: A systematic review and quality assessment, Journal of Adolescent Health, vol. 58(2), pp. 125-133.

[23] Subrahmanyam, K., Šmahel, D. and Greenfield, P. M. (2006). Connecting developmental processes to the Internet: Identity presentation and sexual exploration in online teen chatrooms, Developmental Psychology, vol. 42, pp. 1-12.

[24] Cuadrado, I. (2012). Repetition, Power Imbalance, and Intentionality: Do These Criteria Conform to Teenagers' Perception of Bullying? A Role-Based Analysis, Journal of Interpersonal Violence, vol. 27(10), pp. 1889-1910. 


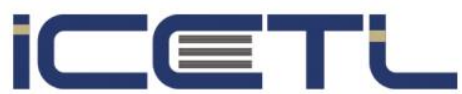

21-23 FEBRUARY, 2020

\section{$3^{\text {rd }}$ International Conference on Research in EDUCATION, TEACHING and LEARNING}

ROME, ITALY

[25] Straude-Müller, F., Hansen, B. and Voss, M. (2012). How stressful is online victimization? Effects of victim's personality and properties of the incident, European Journal of Developmental Psychology, vol. 9, pp. 260-274. 